\title{
Anterior Cruciate Ligament Reconstruction using the Gore-tex Ligament
}

Capt G W Bowyer

MA(Camb), FRCS, RAMC

Registrar in Orthopaedics

Maj S J E Matthews

FRCS(Ed), FRCS, RAMC

Senior Registrar in Orthopaedics

Department of Orthopaedics, Queen Elizabeth Military Hospital, Stadium Road, Woolwich, London SE184QH

SUMMARY: Twenty two Army patients with synthetic (Gore-tex) anterior cruciate ligament (ACL) reconstructions were reviewed (mean follow up 18 months).

Reconstruction appeared to abolish the pivot shift sign in all cases, but some subjective instability persisted in all but 6 patients.

Outcome was also assessed by medical (PULHHEEMS) grading: 6 patients were fully fit (graded $\mathrm{L}_{2}$ ), 7 returned to moderate activity but not full fitness $\left(L_{3}\right)$, and 9 remained severely incapacitated $\left(L_{7}\right.$ or $\left.L_{8}\right)$ with 4 of this group being medically discharged.

Specific operative complications included: prosthesis breakage ( 3 partial, 1 complete), infected prosthesis(1), and problems with the tibial screw(3). The range and frequency of complications was similar in other series.

Physical fitness is an integral part of a soldier's job, placing particular demands on the knee and on surgical repair of knee injuries. Reports on the Gore-tex ACL prosthesis in other groups have been more encouraging, but there are difficulties in comparing this study with others.

ACL insufficiency remains a serious problem, with implications for a soldier's fitness and career. The Gore-te prosthesis improves stability but does not always allow a soldier to return to full fitness.

"It is a matter of common knowledge that cases of rupture of the crucial ligaments are now much more frequently recognised than formerly..."

Major Hey Groves RAMC

'Operation for the repair of the crucial ligaments' Lancet 1917.

\begin{abstract}
"It is now accepted that rupture of the anterior cruciate ligament are both common and disabling. A full realization ... . that the ligament is regularly torn in sporting accidents has only been appreciated in the last two decades. . ."

\section{MF Macnicol \\ 'The torn anterior cruciate ligament' J R Coll Surgeons Edinburgh 1989}

\section{Introduction}

The treatment of $\mathrm{ACL}$ injuries reported around the early years of the 20 th century shows diversity of operations used.

In 1895 Mayo Robson treated a miner whose knee had been grossly unstable for nearly a year following an injury; at arthrotomy both cruciates were found to be torn from their proximal attachments. Catgut was used to suture the shredded ends to tissues on the side of the appropriate femoral condyles, within the femoral notch. His House Surgeon carried out a follow-up visit about 6 years post-operatively, and found the patient able to work, and describing the knee as strong. Mayo Robson addressed the Clinical Society of London in 1902, on the repair of ruptured crucial (sic) ligaments(1) and described this case. He also made reference to the repair of an acutely ruptured ACL which had been carried out by WH Battle in 1898 .

In 1913 Robert Jones(2) advocated withholding immediate operation on the cruciate deficient knee, and employing splintage of the knee for a period of 3 to 6 months to offer the best chance of recovery. However, he gave Hogarth Pringle credit for treating a case by primary re-attachment of the ACL and avulsed tibial spine in 1907, agreeing that this was appropriate for injuries where the tibial spines were involved.

In 1917 Hey Groves carried out an operation to form a new ACL from the ilio-tibial band, and a new posterior 
cruciate from the semitendinosus tendon. The femoral attachments of the tendons were maintained, tunnels created, and the distal ends sutured to the tibia. The patient is reported to have regained strength, stability and movement, and to have returned to work(3).

Thus from 1895 to 1917 there are descriptions of conservative treatment, primary suture of the ligament, re-attachment of the bony insertion, and ligament substitution using autogenous tissue. In the past two decades artificial materials such as carbon fibre and Gore-tex have been added to the treatment options. None the less, the techniques used at the turn of the century continue to be used and modified.

However, Smillie's 1946 pronouncement(4) still holds true, "no treatment can restore perfection of function", and one may infer from the variety of treatment options that there is no single sure answer to the problem of the ruptured $A C L$.

Anterior cruciate ligament (ACL) injuries are common in the young, fit military population. They can be devastating for a soldier's fitness and his military career. Intra-articular reconstruction with a synthetic ligament for the ACL deficient knee has gained in popularity over the past decade; we assess retrospectively the use of the polytetrafluoroethylene (PTFE, Gore-tex) prosthetic ligament in servicemen.

\section{The Gore-tex ACL Replacement}

The Gore-tex prosthesis is a permanent structure designed as a replacement for the natural ligament, with no need for tissue ingrowth or autograft to supplement it. The material used, PTFE, has a greater ultimate tensile strength than the human ACL, with suitable creep and fatigue characteristics(5) to allow its use as an ACL prosthesis. It is fixed to the femur and tibia using screws.

Surgical techniques for placement of the ligament are evolving. The 'over the top' position places the proximal end of ligament above and posterior to the lateral femoral condyle. An elegant study by Odensten and Gillquist(6) showed that this position results in elongation of the ligament by an average of $10 \mathrm{~mm}$ between full flexion and full extension. There followed a search for an 'isometric' position for the ligament in which there would be no length changes throughout the full range of movement. Testing(7) of cadaveric knees under operative conditions has shown no true isometric position, but has demonstrated that lengthening of up to $3 \mathrm{~mm}$ may be physiological and acceptable. This can be achieved by drilling tunnels for the ligament in the femur and tibia. Alignment of these tunnels with the axis of the ligament reduces wear on the prosthesis. Furthermore, widening of the femoral notch by a 'notchplasty' may reduce abrasion of the ligament.

In the cases reviewed here the Gore-tex ligament was inserted using 2 incisions, to approach the femur and tibia; tunnels were drilled to attempt near isometric placement of the prosthesis. A notchplasty was carried out when the condyles were considered to encroach on the prosthesis.

Rehabilitation began with straight leg raises and static quadriceps exercises as soon as possible postoperatively. After 48 hours the continuous passive motion (CPM) machine was used, increasing flexion as comfort allowed over the next few days. Partial weight bearing was permitted at 5 days post-operation, and hydrotherapy was commenced after removal of skin sutures on day 10. Admission to the Defence Services Medical Rehabilitation Unit (DSMRU) at Headley Court followed about 2 months after the operation. There the patient undertook a graded programme of physiotherapy which aimed at improving the lower limb muscles, particularly the hamstrings to bring the hamstring to quadriceps strength ratio up to $1: 1$. The intention was also to improve proprioception about the knee.

Medical grades were allocated on discharge from DSMRU, and subsequently as required on review.

\section{Patients and Methods}

The notes of 22 servicemen or women who had undergone Gore-tex ACL replacement at the Queen Elizabeth Military Hospital (QEMH) over the $2 \frac{1 / 2}{2}$ yea 5 period June 1986 to January 1989, were reviewed. Each patient had been fully fit, with a lower limb medicafo grading of $L_{2}$ before the injury. The mean age of these patients at reconstruction was 25 years 3 months (Fig 1) There was only one female patient.

All patients had chronic ACL insufficiency with af least 6 months between injury and reconstruction (Figo 2). Each patient had failed to respond to conservative management with physiotherapy, which included intensive therapy at DSMRU in 11 of the 22 cases. Selection for ACL replacement was on the basis of continuing serious instability, interfering with work and daily activities. Reconstruction was carried out by one of three consultant orthopaedic surgeons working at QEMH.

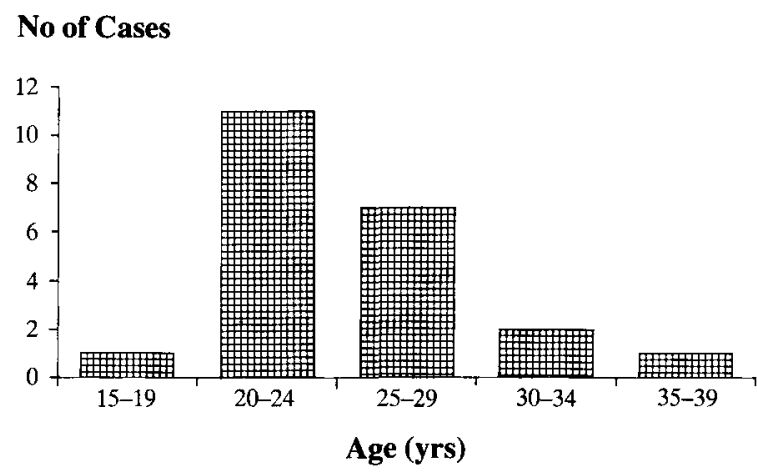

Fig 1. Age at Operation 
No of Cases

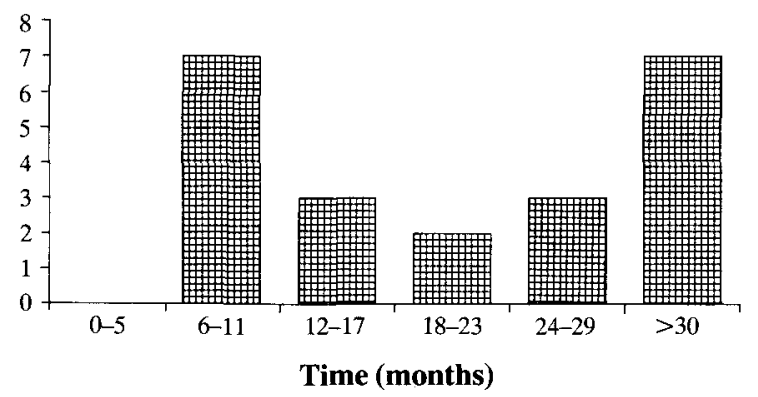

Fig 2. Time from Injury to Operation

The symptoms noted were those of overt instability with giving way, apprehension or subjective instability.

The pre-operative signs of instability (anterior drawer, Lachman's sign, pivot shift test and tests of collateral stability) were elicited in clinic or under general anaesthetic. The postoperative signs were all elicited in clinic.

The hospital notes, proceedings of medical boards and summaries from Headley Court were used to assess the disposal and medical grading of these military patients, as well as recording any specific complications.

\section{Results}

The activity at the time of injury was most often sport: rugby 8 , soccer 6 , ski-ing 1 , running 1 , falls in other activities 3 . The initial injury could not be recalled in 3 cases.

Pathology in addition to rupture of the ACL was commonly found at initial examination under anaesthetic and arthroscopy (15 of 22 patients). Eight patients had a meniscectomy or partial meniscectomy in the time between injury and reconstruction. Associated pathology is indicated in Table 1.

Eleven patients had evidence of progression of the intra-articular pathology between first arthroscopy and ACL reconstruction; 5 of these patients had undergone a meniscectomy. The nature of the progression is indicated in Table 2.

Pre- and postoperative signs, outcome in terms of stability, activity and the latest medical grading, length of follow up and specific complications are given in Table 3.

The mean follow up was 18 months from reconstruction.

Outcome - Symptoms Ten patients had a symptomfree knee after the reconstruction; this did not always correlate with a return to full fitness, as is shown in Table 3. Four patients had persistent feeling of instability without actual giving way, but in 5 cases the knee continued to give way after reconstruction. Knee pain,
Table 1

Pathology Associated with ACL Tear

\begin{tabular}{|c|c|c|}
\hline \multirow{2}{*}{ Meniscal Tears } & Medial Meniscus & 8 \\
\hline & Lateral Meniscus & \\
\hline \multirow[t]{3}{*}{ Ligamentous Tears } & Posterior Cruciate & \\
\hline & Medial Collateral & \\
\hline & Lateral Collateral & \\
\hline
\end{tabular}

13 of the 22 patients with ACL tears had an associated injury to another structure within the same knee.

Table 2

Progression of Intra-Articular Pathology

New Meniscal Tears/Scuffs Medial

Femoral Condylar Wear Medial

Lateral

11 of the 22 patients with ACL insufficiently showed sign? of progressive damage within the knee between firsi arthroscopy and ACL reconstruction.

particularly on exertion remained a problem in patients following reconstruction. In one case there were problems of apprehension on exertion, rather tha्? true instability.

Outcome-Signs Pre-operatively all patients had a 'full house' of ACL instability: anterior drawer, Lachman and pivot shift. Although the Lachman and/or anterior drawer signs persisted postoperatively in 13 patients, there was no record of a pivot shift sign being elicited after the ACL reconstruction.

Outcome-Medical Grading The most recent medical grading of lower limb function can be used as an $\vec{\Phi}$ indicator of outcome (Fig 3): 6 were fully upgraded to the highest category in current use $\mathrm{L}_{2}$,

7 (including the servicewoman) were able to march $\frac{5}{3}$ and stand for sufficient periods to be graded $\mathrm{L}_{3}$,

5 could manage to walk only a couple of miles and were graded L7,

4 patients were not able to return to active 옥 employment and were felt unfit for any further military $\frac{7}{0}$ service and discharged at $\mathrm{L}_{8}$.

Complications The specific complications in this series were: ligament rupture which was either complete $(1$ N case) or partial (3 cases), problems with the anchoring ${ }_{0}^{\omega}$ tibial screw ( 3 cases) and deep seated sepsis (1 case). 
Table 3

Summary of Complications

\begin{tabular}{|c|c|c|c|c|c|c|}
\hline $\begin{array}{l}\text { Case } \\
\text { No. }\end{array}$ & $\begin{array}{l}\text { Pre-Op } \\
\text { Signs }\end{array}$ & $\begin{array}{l}\text { Post-Op } \\
\text { Symptoms }\end{array}$ & $\begin{array}{l}\text { Post-Op } \\
\text { Signs }\end{array}$ & $\begin{array}{c}\text { Latest } \\
\text { PULHEEMS }\end{array}$ & $\begin{array}{c}\text { Implant } \\
\text { Complications }\end{array}$ & $\begin{array}{c}\text { Total } \\
\text { Follow-up }\end{array}$ \\
\hline 1 & LAP & Gives way & Stable & P8L8 & Nil & 2 years \\
\hline 2 & LAPE & Stable & LA & P2L2 & Nil & 13 months \\
\hline 3 & $\begin{array}{l}\text { LAP } \\
\text { mcl }\end{array}$ & S1. unstable & $\underset{\mathrm{mcl}}{\mathrm{L}}$ & P7L 7 & $\begin{array}{l}\text { Complete rupture of } \\
\text { ligament at } 6 \text { mnth }\end{array}$ & 14 months \\
\hline 4 & $\begin{array}{l}\text { LAP } \\
\text { pcl, mcl }\end{array}$ & Gives way & $\begin{array}{c}\mathrm{LAE} \\
\mathrm{pcl}, \mathrm{mcl}\end{array}$ & P8L8 & $\begin{array}{l}\text { Partial rupture of } \\
\text { ligament }(20 \%)\end{array}$ & 16 months \\
\hline 5 & LAP & Stable & Stable & P3L3 & Nil & 8 months \\
\hline 6 & LAP & Stable & $\mathrm{E}$ & P2L2 & $\begin{array}{l}\text { Synovitis and } 30 \% \\
\text { ligament rupture }\end{array}$ & 3 years \\
\hline 7 & LAP & S1 unstable & LA & P7L7 & Nil & 13 months \\
\hline 8 & LAP & Apprehension & LA & P3L3 & Nil & 10 months \\
\hline 9 & $\begin{array}{l}\text { LAP } \\
\text { mcl }\end{array}$ & Gives way & $\begin{array}{l}\mathrm{LA} \\
\mathrm{mcl}\end{array}$ & P3L7 & Nil & 3 years \\
\hline 10 & LAP & Stable & $\mathrm{L}$ & P3L3 & Nil & 10 months \\
\hline 11 & LAP & Stable & Stable & P3L3 & Nil & 11 months $\frac{\widetilde{\Phi}}{\mathbb{D}}$ \\
\hline 12 & $\begin{array}{l}\text { LAP } \\
\text { pcl,licl }\end{array}$ & Gives way & $\begin{array}{l}\mathrm{LE} \\
\mathrm{pcl}, \mathrm{lcl}\end{array}$ & P8L8 & Nil & 5 months \\
\hline 13 & LAP & $\begin{array}{l}\text { Pain \& sl. } \\
\text { unstable }\end{array}$ & Stable & P8L8 & Screw loosened & 21/2 years $\stackrel{0}{\leftrightarrows}$ \\
\hline 14 & $\begin{array}{l}\text { LAP } \\
\text { mcl }\end{array}$ & Stable & $\underset{\mathrm{mcl}}{\mathrm{A}}$ & P3L3 & Nil & $21 / 2$ years \\
\hline 15 & LAP & Stable & Stable & P2L2 & Nil & $31 / 2$ years \\
\hline 16 & LAP & $\begin{array}{l}\text { Knee pain on } \\
\text { exertion }\end{array}$ & LA & P3L7 & $\begin{array}{l}\text { Deep seated sepsis } \\
\text {-ligament removed }\end{array}$ & 14 months \\
\hline 17 & LAPE & $\begin{array}{l}\text { Knee pain on } \\
\text { exertion }\end{array}$ & Stable & P3L 3 & Nil & 4 months \\
\hline 18 & LAP & Stable & Stable & P2L2 & Nil & 11 months \\
\hline 19 & LAP & Stable & Stable & P2L2 & Pain at screw site & 3 years \\
\hline 20 & LAP & Gives way & LA & P7L7 & Nil & 3 months \\
\hline 21 & LAP & S1. Unstable & A & P3L3 & Pain at screw site & 9 months \\
\hline 22 & LAP & Stable & $\mathrm{AE}$ & P2L2 & Nil & 3 years \\
\hline
\end{tabular}

Key to abbreviations:
L Lachmans sign positive
A Anterior drawer sign positive
P Pivot shift test positive
E Effusion present
pel Signs of Posterior Cruciate Ligament laxity
mcl Medial Collateral Ligament laxity
Icl Lateral Collateral Ligament laxity
S1 Instability implies sensation of instability without giving way 
The patient with complete rupture of the ligament had no clear history of re-injury. His knee remained unstable post reconstruction, and arthroscopy at 6 months confirmed the ligament as broken. This was replaced soon afterwards, but with little symptomatic improvement.

Persistent moderate to severe effusions for nearly 2 years led to one patient being re-arthroscoped; approximately $30 \%$ of the Gore-tex fibres were broken. Synovial biopsy revealed chronic proliferative nonspecific synovitis, with no evidence of Gore-tex fragments within the tissue, and negative bacterial culture. The effusion subsequently settled and the patient went on to have an asymptomatic knee with no further effusions.

The partial ligament rupture in the other 2 cases was discovered when the knee was arthroscoped for a haemarthrosis following further injury. One knee had otherwise been symptomatically stable, with no signs of cruciate laxity; in this case less than $30 \%$ of the ligament was ruptured, and the patient went on to a full symptomatic recovery. In the other patient $20 \%$ of the Gore-tex fibres were noted to be worn through, and there was also a new medial meniscal tear which was trimmed; this was one of the patients with concommitant PCL insufficiency, who had a poor outcome.

In 1 patient a septic arthritis developed insidiously a few weeks postoperatively. Despite vigorous antibiotic therapy the ligament had to be removed. This patient has subsequently been managed conservatively using a knee brace, and remains active but not fully medically upgraded.

A prominent tibial screw or aching pain at the screw site caused annoying but not disabling problems in 2 patients. This settled after steroid injections at the screw site. In one patient the tibial screw actually broke 20 months postoperatively. The ligament remained intact,

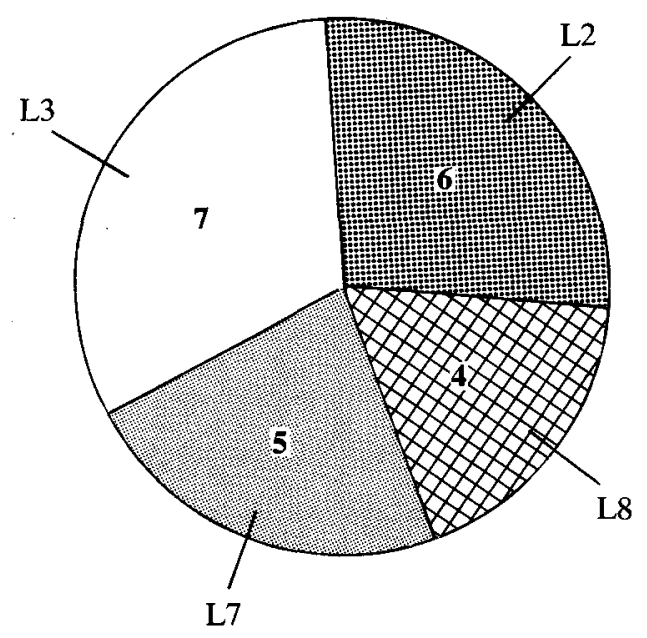

Fig 3. Outcome of Reconstruction - Medical Grading so a new screw was inserted. This patient failed to regain full fitness and could not run, despite being able to cycle and swim; he felt unable to continue Army service, and was one of the patients given a medical discharge.

\section{Discussion}

It must be emphasised that Gore-tex ACL reconstruction was offered only as a salvage procedure, to patients for whom conservative measures had been exhausted and yet remained severely incapacitated by instability. They accepted the risks of a procedure for which there was little data on long-term results.

Of the 11 patients in our series with evidence of progressive intra-articular disease, 6 had undergone a previous meniscectomy. Others(8) have demonstrated progressive pathology in knees with ACL deficiency. There has been discussion as to whether this is a result of the ACL laxity itself altering the dynamics of the knee $(9)$, or a consequence of the associated meniscal damage or meniscectomy $(10,11)$ which alters the load bearing.

Whatever the actual cause of the progressive damage, it is not clear whether stabilization of the knee, as shown by absence of the pivot shift, will reduce or arrest the progress of wear within the ACL deficient knee. This is obviously important, quite apart from any effect surgeryo may have on the symptomatic or functional stability, and should be the subject of further study.

The 2 patients with concommitant $\mathrm{ACL}$ and $\mathrm{PCL}^{\circ}$ disruption did not do well; they did not have a symptomatically stable knee after ACL reconstruction. In one case the knee continued to give way, and the patient was given a $\mathrm{L}_{8}$ medical discharge from the Armyo The other patient managed to regain a fair degree of activity and was graded to $L_{3}$, but later suffered a setback with the knee giving way as he stepped down from a truck, causing further injury to the knee, requiring a partial medial meniscectomy. Subsequent instability and restriction of running led to an $\mathrm{L}_{8}$ medical discharge.

Symptoms of persistent instability which prevented running were the reason for the other 2 patients seeking and being granted a medical discharge at $\mathrm{L}_{8}$.

The medical grading system gives a useful and appropriate measure of the result obtained in servicemen, as it indicates the patient's capacity for his work as a soldier. Considering grade $\mathrm{L}_{2}$ as good, $\mathrm{L}_{3}$ as fair, and grades $\mathrm{L}_{7}$ and $\mathrm{L}_{8}$ as poor, the results can be interpreted as: Good 27\%, Fair 32\%, Poor $41 \%$.

Early reports on the use of Gore-tex as a prosthetic ligament were encouraging. Ahlfield et al(12) reported on 30 patients, in 27 of whom the pivot shift sign was abolished postoperatively, the result being considered satsifactory in $26(87 \%)$ at an average of 2 years follow up. Indelicato et al(13) used the Gore-tex prosthesis in 41 patients and reviewed 39 of them at 2 years postoperatively. The result was satisfactory in $34(87 \%)$ of these patients. Clearly these results are good, but not 
directly comparable with the outcome in our cases.

The range of complications reported by others using the Gore-tex ligaments is comparable with that in our series. The incidence of specific complications in our series is similar to that reported by Indelicato et al(13), who found 2 complete prosthesis tears in the 39 cases reviewed, and 1 case of sepsis which led to removal of the ligament. They reported 9 patients with episodes of atraumatic sterile effusions: in 5 of these there were minor tears of the prosthesis, with evidence of Gore-tex particles within the synovium in 3 . They postulated that the abraded material may have caused the effusion. Minor problems of irritation over the tibial or femoral screws occurred in 3 patients.

There are limitations to a retrospective study, and difficulties in comparing our results with other series. The problems are in the 4 main areas of bias in orthopaedic research, identified by Rudicel and Esdaile(14): susceptibility, performance, detection and transfer bias.

Susceptibility bias arises when comparison is made between groups which are prognostically dissimilar. The military requirement for fitness as an essential part of the job, and regular fitness testing, may place different stresses on this population compared with a civilian group. They could be regarded as athletes, for whom sport and fitness is an integral part of their occupation, rather than a pastime. The demands of this young group, and their expectations, are high.

Our inclusion of 2 patients with PCL rupture in association with their ACL damage may adversely bias our results: a patient in another series(13) with symptomatic PCL instability also did poorly.

Much has been written about the selection of patients suitable for ACL surgery $(9,15,16)$, and attempts have been made to identify risk factors(17) influencing the outcome and natural history of ACL deficiency. Essentially these depend on the patients' symptoms, the demands placed on the knee and the willingness or otherwise to adjust or adapt sporting activity. Different criteria are applied by different authors, and this selection of dissimilar groups may influence the outcome of surgery.

Performance bias is due to differences in the techniques and expertise of the surgeon, the back-up and the rehabilitation services. A relatively large experience of the procedure has been built up at QEMH, with more than 50 cases having been operated on. The rehabilitation programme at DSMRU Headley Court is a well-established regimen.

Detection bias arises when the methods of assessment, grading of results and follow up vary between authors. The grading systems used by the various clinicians involved in assessing pre- and postoperative signs in our patients were not consistent, so we limited ourselves to indicating whether a particular sign was elicited or not, and did not attempt to give any grading to these. More reliable results are obtained if assessment is by investigators using objective data $(10)$, or a standard scoring scale is used for the follow-up(18). An instrument such as the Medtronics KT1000 can be used to give objective data $(11,13)$ for ligamentous laxity, but some have doubted its value and reliability(19).

The presence of a pivot shift sign is regarded as evidence of severe ACL insufficiency $(15,18)$. This is essentially a dynamic test of antero-lateral instability; whilst it is encouraging to see that no pivot shift was detected in any patient after reconstruction, there may well be false negatives in this result, since few patients had cause for an examination under anaesthetic after the reconstruction. It is often difficult to elicit this sign in the un-anaesthetised patient, particularly if he has previously been subjected to that test when conscious, as the manoeuvre is then resisted.

Transfer bias is the loss of patients to adequate follow up. The mean of 18 months follow up in this series is acceptable for evaluation of the early results. However, 3 patients were seen finally less than 6 months from their operation, and one was not reviewed in clinic postoperatively; this makes the transfer bias regrettably high.

Noyes, McGinniss and Grood(20), and Bray, Flanagan and Dandy(21) have shown a deterioration ito the results of ACL reconstruction between 3 and 6 years post-operation. They have stressed the need for follo up beyond 5 years in order to assess a ligament reconstruction.

\section{Conclusion}

Disruption of the ACL is a serious injury, with unfavourable implications for a soldier's fitness arf career. For those with chronic ACL instability for whon conservative measures had failed, the Gore-tex prosthesis has been shown to give a good or fair result in $59 \%$ of cases, in the short term. None the less, this ligament reconstruction offers no guarantee of a return to the standards of lower limb fitness demanded by the highest medical grading: only 6 out of 22 patients $(27 \%)$ were fully upgraded.

\section{Acknowledgement}

We are most grateful to Brigadier D G Stock and $\mathrm{Mr}$ A Qureshi for their permission to include their patients in this report, and to Lt Col A F G Groom for advice on its preparation.

Some of the material was used in a presentation to the Defence Medical Services surgical meeting at Royal Army Medical College, Millbank in July 1990.

\section{REFERENCES}

1. Robson A W M. Ruptured crucial ligaments and their repair by operation. Ann Surg 1903; 37: 716-18.

2. JoNES R, SMITH S A. On rupture of the crucial ligaments of the knee, and on fractures of the spine of the tibia. $\mathrm{BrJ}$ Surg 1913; 1: 70-89. 
3. Hey Groves E W. Operation for the repair of the crucial ligaments. Lancet 1917; 2: 674-8.

4. Smillie I S. Injuries of the knee joint. Edinburgh. E\&S Livingstone, 1946: 111.

5. Zoltan D J, Reinecke C, Indelicato P A. Synthetic and allograft anterior cruciate ligament reconstruction. Clin Sports Med 1988; 7: 773-84.

6. Odensten M, Gillouist J. Functional anatomy of the anterior cruciate ligament and a rationale for reconstruction. J Bone Joint Surg 1985; 67A: 257-62.

7. Sapega A A, Moyer R A, S Chneck C, Komalahiranya $N$. Testing for isometry during reconstruction of the anterior cruciate ligament. J Bone Joint Surg 1990; 72A: 259-67.

8. Kannus P, Jarvinen M. Conservatively treated tears of the anterior cruciate ligament. J Bone Joint Surg 1987; 69A: 1007-12.

9. Noyes F R, MCGinniss G $H$. Controversy about the treatment of the knee with anterior cruciate laxity. Clin Orthop 1985; 198: 61-76.

10. MCDAniEL W J, Dameron T B. Untreated ruptures of the anterior cruciate ligament. J Bone Joint Surg 1980; 62A: 696-705.

11. MaCnicol $M F$. The torn anterior cruciate ligament. $J R$ Coll Surg Edinb 1989; 34(suppl): S4-S11.

12. Ahlfield S K, Larson R L, Collins H R. Anterior cruciate reconstruction in the chronically unstable knee using an expanded polytetrafluoroethylene (PTFE) prosthetic ligament. Am J Sports Med 1987; 15: 326-330.
13. Indelicato P A, Pascale M S, Huegel M O. Early experience with the Gore-tex polytetrafluoroethylene anterior cruciate ligament prosthesis. Am J Sports Med $1989 ; 17: 55-62$.

14. Rudicel S, EsDaile J. The randomized clinical trial in orthopaedics. Obligation or option? J Bone Joint Surg $1985 ; 67 \mathbf{A} ; 1284-93$.

15. Sandberg R, Balkfors B, Nilsson B, Westlin $\mathbf{N}$. Operative versus non-operative treatment of recent injuries to the ligaments of the knee. J Bone Joint Surg 1987; 69A: 1120-6.

16. HoLDEN D L, JACKSON D W. Treatment selection in acute anterior cruciate ligament tears. Orthop Clin North Am 1985; 16: 99-109.

17. Noyes F R, MCGinniss G H, Mooar P A. Functional disability in the anterior cruciate insufficient knee syndrome. Sports Med 1984; 1: 278.

18. LySholm J, Gillouist J. Evaluation of knee ligament surgery results with special emphasis on use of a scoring scale. Am J Sports Med 1982; 10: 150-4.

19. Forster I W, Warren Smith C D, Tew M. Is the KT1000 knee ligament arthrometer reliable? J Bone Joint Surg 1989; 71B: 843-7.

20. Noyes F R, McGinniss G H, Grood E S. The variable functional disability of the anterior cruciate ligament deficient knee. Orthop Clin North Am 1985; 16: 47-67.

21. BRay R C, Flanagan J P, Dandy D J. Reconstruction for chronic anterior cruciate instability. J Bone Joint Surg 1988; 70B: 100-5.

\section{ACADEMIC ACHIEVEMENTS}

DLO

\section{MRCGP}

$\operatorname{MSc}$ (General Practice)
Major T R Whelan, RAMC

Major S M Matthews, RAMC

Colonel J C Richardson, L/RAMC 